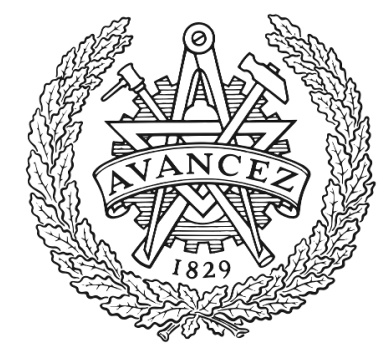

\title{
CHALMERS
}

UNIVERSITY OF TECHNOLOGY

\section{LiFePO4 Battery Modeling and Drive Cycle Loss Evaluation in Cascaded H-Bridge Inverters for Vehicles}

Downloaded from: https://research.chalmers.se, 2023-04-26 13:06 UTC

Citation for the original published paper (version of record):

Theliander, O., Kersten, A., Kuder, M. et al (2019). LiFePO4 Battery Modeling and Drive Cycle Loss Evaluation in Cascaded H-Bridge Inverters for

Vehicles. ITEC 2019 - 2019 IEEE Transportation Electrification Conference and Expo, June 2019:

1-7. http://dx.doi.org/10.1109/ITEC.2019.8790460

N.B. When citing this work, cite the original published paper. 


\title{
$\mathrm{LiFePO}_{4}$ Battery Modeling and Drive Cycle Loss Evaluation in Cascaded H-Bridge Inverters for Vehicles
}

\author{
Oskar Theliander ${ }^{1}$, Anton Kersten ${ }^{1}$, Manuel Kuder ${ }^{2}$, Emma Grunditz $^{1}$, and Torbjörn Thiringer ${ }^{1}$ \\ ${ }^{1}$ Chalmers University of Technology, Gothenburg, Sweden \\ Email: kersten@chalmers.se \\ ${ }^{2}$ University of the German Federal Armed Forces, Munich, Germany \\ Email: manuel.kuder@unibw.de
}

\begin{abstract}
This paper deals with the modeling and parameterization of $\mathrm{LiFePO}_{4}$ batteries when used in cascaded $\mathrm{H}$-bridge multilevel inverter drive systems. Since the battery packs are intermittently conducting the motor currents, the battery cells are stressed with a dynamic current waveform containing a substantial amount of low order harmonic components in the range of a couple of $\mathrm{kHz}$. Different battery models like a pure resistive or different $\mathrm{RC}$ networks are considered, to determine the battery losses. Measurements of the voltage drop for a pulsed current of variable frequency and magnitude are done to be able to determine the model parameters. The models are then verified against measurements on a battery pack placed in a small scale multilevel inverter operated at 6 different operating point that are representative for the operation of an electrified vehicle. It is shown that the dynamic model agrees very well with the measurements for all operating points analyzed with a maximum deviation of $4 \%$. The results are also compared with the commonly used resistive model which overestimates the losses with typically around $20 \%$ for the evaluated points. Simulations of $\mathbf{4}$ full drive cycles are performed where it is stated that the resistive model always shows about $20 \%$ more losses compared to the 3 time constant model.
\end{abstract}

\section{INTRODUCTION}

The two-level inverter is wide spread and vastly used for the propulsion in today's battery electric vehicles [1]-[3]. However, multilevel inverters are gaining interest for vehicle applications like the Neutral Point Clamped (NPC) inverter or the Cascaded H-bridge (CHB) inverter. These inverter topologies have several advantages compared to the classical two-level inverter, as for example fault tolerant operation possibility, efficiency enhancement and especially low output voltage harmonic and disturbance emissions [4]-[8]. In [8], [9] the cascaded H-bridge topology is considered, while an additional battery paralleling is achieved with the split battery system described in [10]. These multilevel topologies achieve a high inverter efficiency by the usage of low voltage MOSFETs, which in addition come with a low cost. Each battery pack can be drained by its individual capacity, so that the amount of energy in the battery can be utilized to its full extent. However, the battery packs are subject to a current far from DC, containing a substantial amount of low order harmonics [11], which make the energy efficiency calculation difficult.

Different models to describe the battery behaviour with electrical equivalent circuit are discussed in [12]-[16]. A lot of work to parameterize the battery system for dynamic simulations and loss evaluations in hybrid and pure electric vehicles has been done in [17]-[22]. However, the presented models are used to describe the battery system of a classical twolevel inverter drive system. Therefore, these do not consider the frequency components (DC to a couple of $\mathrm{kHz}$ ) that the battery cells in a multilevel inverter drive system are subject to. Moreover, lacking in literature is also a quantification of the energy efficiency consequences when using a dynamic battery model compared to a pure resistive model or an EIS identified model.

The contribution of this article is to characterize and to verify the battery performance when used in a CHB inverter for an electrified vehicle. Moreover, also to quantify the importance of using a dynamic model compared to using the classical resistive model.

\section{CASCADED H-BRIDGE TOPOLOGY AND CONTROL}

The Cascaded H-Bridge converter consists of series connected H-bridges, which can be independently controlled. Within the scope of this investigation, a seven level CHB inverter is considered, as shown in Fig. 1. Every H-bridge has

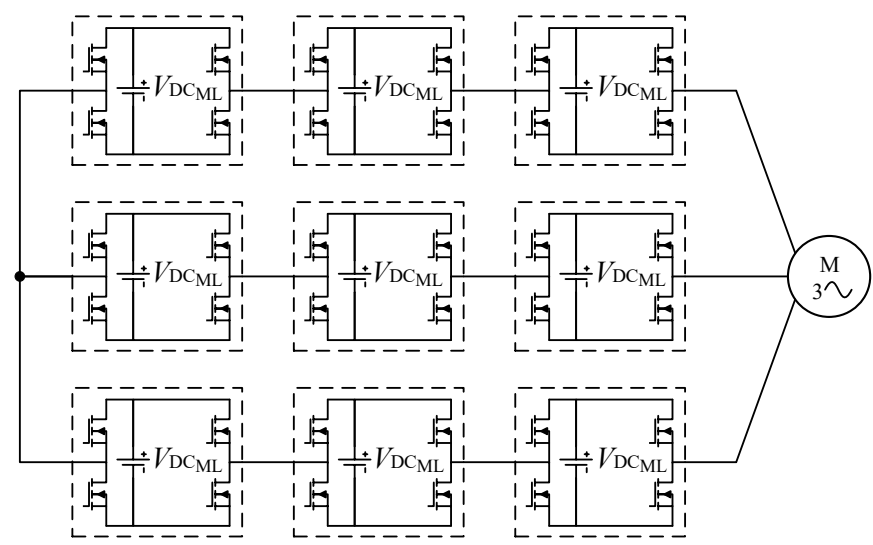

Fig. 1: 7-level cascaded H-bridge drive system with separate battery packs.

a battery pack attached to it. By controlling the switches in the $\mathrm{H}$-bridge in pairs, one module can create the output voltage

$$
V_{\mathrm{HB}}=\left\{V_{\mathrm{DC}_{\mathrm{ML}}},-V_{\mathrm{DC}_{\mathrm{ML}}}, 0\right\},
$$

where $V_{\mathrm{DC}_{\mathrm{ML}}}$ describes the nominal battery pack voltage. Having $n$ modules in series connected, the number of voltage 
levels per phase becomes

$$
m=2 n+1 \text {. }
$$

In literature, several modulation techniques can be found to control the output voltage of a multilevel inverter [23]-[26]. For this investigation, the chosen modulation technique to control the output voltage of the inverter is Fundamental Selective Harmonic Elimination (FSHE) [24]. This technique achieves a high drive train efficiency at high speeds, since the switching losses are kept to a minimum, while a selection of low order harmonics are eliminated [9]. By choosing the proper time instants to turn on and turn off the switches of the different H-bridges in the multilevel inverter, the amplitude of the fundamental frequency as well as a selection of harmonics are controlled. For an $m$-level inverter, the amplitude of the fundamental frequency and $\frac{m-3}{2}$ harmonic components can be controlled. Since the motor inductance acts as a current low pass filter, it is of utmost importance to minimize the low frequency voltage harmonics, as for example the 5th and the 7 th harmonic. The voltage waveform built up by the 7-level inverter can be expressed with the help of the switching angles $\alpha_{1}, \alpha_{2}$ and $\alpha_{3}$. The angles describe the instants when $\mathrm{H}$-bridge 1 to 3 should be activated in forward or reverse conduction. According to [24], [27], the fourier series expansion of the signal for the different harmonics, $h$, can be written as

$$
V_{h_{\mathrm{ML}}}=\frac{4 V_{\mathrm{DC}_{\mathrm{ML}}}}{h \pi}\left(\cos \left(h \alpha_{1}\right)+\cos \left(h \alpha_{2}\right)+\cos \left(h \alpha_{3}\right)\right)
$$

Equation (3) assumes that the DC-voltages are equal for all H-bridges. The modulation index can go up to 1.07 without loosing the possibility to eliminate the 5th and 7th harmonic [28]. If the modulation index is below 0.487 , the control over both harmonics is also lost since $\alpha_{1}, \alpha_{2}$ and $\alpha_{3}$ are constrained to $90^{\circ}$. Nevertheless, the harmonics are minimized with a prioritization on the 5 th harmonic. To keep the battery packs balanced, the controller makes sure to use the battery packs according to their capacity. Therefore, during motor operation, the battery pack with the highest voltage and the lowest voltage is used to the largest and smallest extent, respectively, and vice versa during recuperation. The maximum output voltage the inverter can create, while keeping a voltage margin of $10 \%$ to account for the voltage drops and the needed blanking time of the inverter valves, as well as to have a sufficient control margin, can be expressed as

$$
V_{\text {phase }_{\mathrm{RMS}, \mathrm{MAx}}}=0.9 \cdot 1.07 \frac{V_{\mathrm{DC}_{\mathrm{ML}}} \cdot n}{\sqrt{2}} .
$$

The drawn battery pack current of each module can be expressed as

$$
i_{\text {Bat }, j}= \begin{cases}+i_{\text {phase }}, & \text { if } \alpha_{j} \leq \omega t \leq \pi-\alpha_{j} \\ -i_{\text {phase }}, & \text { if } \pi+\alpha_{j} \leq \omega t \leq 2 \pi-\alpha_{j} \\ 0, & \text { else }\end{cases}
$$

with $j=\{1,2 \ldots, n\}$. Fig. 2(a) depicts the inverter output voltage and the motor phase current of one phase for an arbitrary operating point. It can be seen that all three modules are inserted. The drawn battery current in comparison to the average current for battery pack 1 is depicted in Fig. 2(b). It is far from a DC quantity. The fourier analysis of the drawn battery current yields the harmonic components, as depicted in Fig. 3. The battery is stressed with a substantial amount of even low order harmonic components. For this operating point, the magnitude of the first harmonic exceeds even the DC component for the chosen battery pack. In comparison, the DC bus in a classical two-level inverter is stressed with a high frequency ripple corresponding to the switching harmonics [29]-[31].

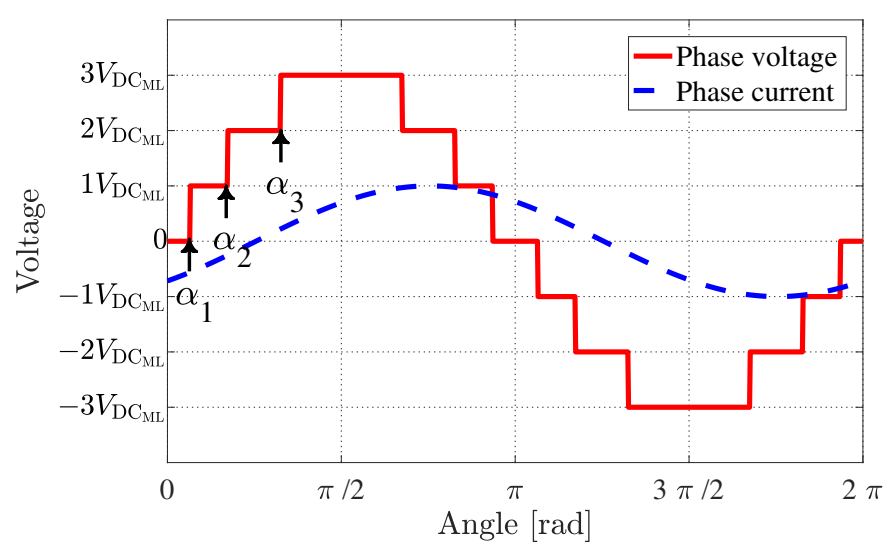

(a)

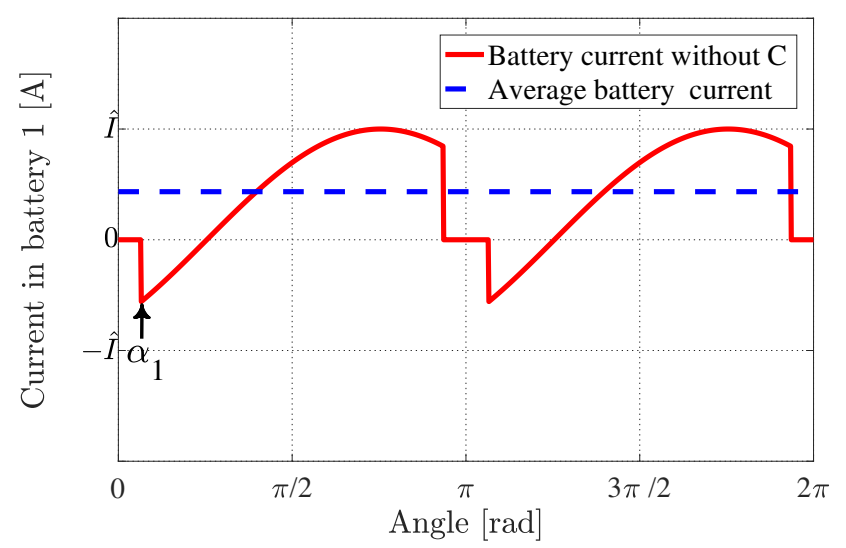

(b)

Fig. 2: Phase voltage and current (a) and drawn battery current (b) for an example operating point.

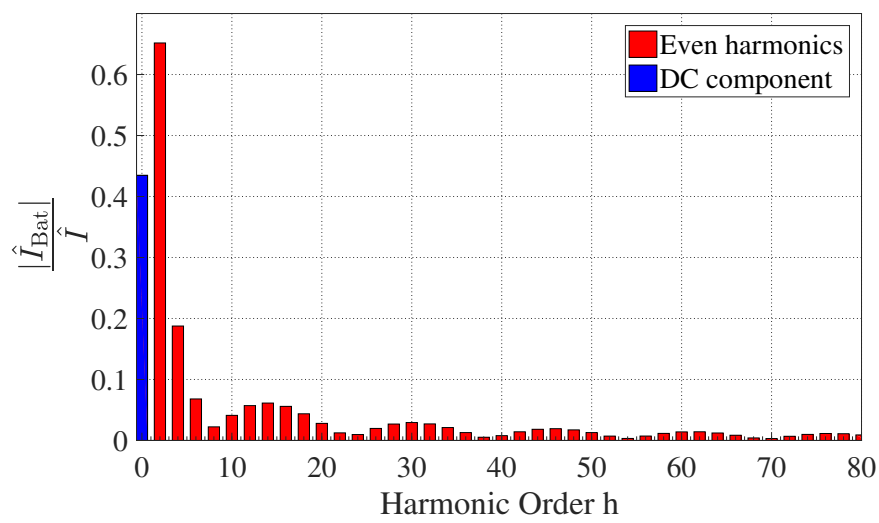

Fig. 3: Harmonic current components of the drawn battery current shown in Fig. 2(b). 


\section{BATtery MODEling AND PARAMETER EXTRACTION}

The battery cell chosen for this investigation is the ANR26650M1A produced by A123 Systems [32]. It is a cylindrical high power cell based on a $\mathrm{LiFePO}_{4}$ chemistry. The nominal voltage is $3.3 \mathrm{~V}$ and the specified capacity is about $2300 \mathrm{mAh}$.

\section{A. Dynamic Battery Modeling}

Several battery equivalent circuit models can be found in [12]-[16]. The conclusion seems to be that the Randles model, as shown in Fig. 4, describes the battery dynamics and the ohmic battery losses adequately. The battery cell is modeled by an RC network. The three time constants, represented by $R_{1}$ to $R_{2}$ and $C_{1}$ to $C_{3}$, are used to describe the transient battery behavior. The resistance $R_{0}$ represents the internal battery resistance. The open circuit voltage $V_{\mathrm{OCV}}$ is dependant on the State of Charge (SOC). Since the frequency range is within a range of a couple of $\mathrm{kHz}$, the battery's series inductance is assumed to be negligible in the further analysis.



Fig. 4: Randles model of a battery cell, using three time constants.

\section{B. Parameter Extraction}

Measurements are done on one battery cell at a characteristic state of charge of about $50 \%$. A resistive load is used, while the cell voltage and current are measured with an oscilloscope. The cell is being stressed with a pulsed current of different magnitudes (28 A and $49 \mathrm{~A})$ and various frequencies $(1 \mathrm{~Hz}$ to $100 \mathrm{~Hz}$ ). The three time constant Randles model shown in Fig. 4 has an impedance that is mathematically described as

$$
Z_{\text {Cell }}(s)=R_{0}+\frac{R_{1}}{s+R_{1} C_{1}}+\frac{R_{2}}{s+R_{2} C_{2}}+\frac{R_{3}}{s+R_{3} C_{3}},
$$

which can be rewritten as

$$
Z_{\text {Cell }}(s)=\frac{b_{3} s^{3}+b_{2} s^{2}+b_{1} s+b_{0}}{s^{3}+a_{2} s^{2}+a_{1} s+a_{0}} .
$$

Using its corresponding poles, $p_{3}, p_{2}$ and $p_{1}$, and zeros, $z_{3}$, $z_{2}$ and $z_{1}$, the cell impedance term becomes

$$
Z_{\text {Cell }}(s)=b_{3} \frac{\left(s-z_{3}\right)\left(s-z_{2}\right)\left(s-z_{1}\right)}{\left(s-p_{3}\right)\left(s-p_{2}\right)\left(s-p_{1}\right)}
$$

This impedance term can easily be parameterized by a leastsquare fit, using the measured voltage and current shape obtained during the pulse test [22]. The equivalent circuit parameters can then be extracted as follows. From the poles, the system time constants are calculated according to

$$
\left[\begin{array}{l}
\tau_{3} \\
\tau_{2} \\
\tau_{1}
\end{array}\right]=-\left[\begin{array}{l}
1 / p_{3} \\
1 / p_{2} \\
1 / p_{1}
\end{array}\right] .
$$

Knowing the time constants, a matrix $\mathrm{A}$ is created according to

$$
A=\frac{1}{\tau_{1} \tau_{2} \tau_{3}} \cdot\left[\begin{array}{cccc}
\tau_{1} \tau_{2} \tau_{3} & 0 & 0 & 0 \\
\tau_{1} \tau_{2}+\tau_{1} \tau_{3}+\tau_{2} \tau_{3} & \tau_{2} \tau_{3} & \tau_{1} \tau_{3} & \tau_{1} \tau_{2} \\
\tau_{1}+\tau_{2}+\tau_{3} & \tau_{2}+\tau_{3} & \tau_{1}+\tau_{3} & \tau_{1}+\tau_{2} \\
1 & 1 & 1 & 1
\end{array}\right],
$$

which can be used to calculate the resistances as

$$
\left[\begin{array}{l}
R_{3} \\
R_{2} \\
R_{1} \\
R_{0}
\end{array}\right]=A^{-1}\left[\begin{array}{l}
b_{3} \\
b_{2} \\
b_{1} \\
b_{0}
\end{array}\right]
$$

The capacitances can now be calculated as

$$
\left[\begin{array}{l}
C_{3} \\
C_{2} \\
C_{1}
\end{array}\right]=\left[\begin{array}{ccc}
\tau_{3} & 0 & 0 \\
0 & \tau_{2} & 0 \\
0 & 0 & \tau_{1}
\end{array}\right]\left[\begin{array}{l}
1 / R_{3} \\
1 / R_{2} \\
1 / R_{1}
\end{array}\right]
$$

If the Randles model is used with two or one time constants, the parameters are calculated in a similar way from the least square fit.

The measurement of a pulsed current of $28 \mathrm{~A}$ and $1 \mathrm{~Hz}$, conducted on a single cell, can be seen in Fig. 5. Furthermore, the simulated voltage shapes for the Randles model, using different time-constants are depicted. The resulting parameters were extracted using the before described approach. The parameters and the normalized root mean square deviation of the curve fits can be seen in Table I. It can be noted that the magnitude fit is excellent when using 3 poles and 3 zeros. Moreover, it can be observed that the impedance becomes a bit higher at higher currents. An Electric Impedance Spectroscopy (EIS) sweep has also been performed in the frequency range of $10 \mathrm{mHz}$ to $10 \mathrm{kHz}$ using a battery cell tester, Gamry reference 3000 [33]. For the EIS sweep, the battery parameters, using 3 poles and 3 zeros, were extracted by a least square fit [16]. The resulting Bode plot for some least-square curve fits of different measurements are shown in Fig. 6. For the further analysis the data set 'meas $3.23 \mathrm{~V} 1 \mathrm{~Hz} 28 \mathrm{~A}^{\prime}$ is chosen. It can be noted that the $2 \mathrm{p} 2 \mathrm{z}, 1 \mathrm{p} 1 \mathrm{z}$ and resistive model do not fit the high frequency behavior very well, but these show a great match at the lower frequency content, where the pulsed waveform goes towards a steady state. However, the $3 \mathrm{p} 3 \mathrm{z}$ fit shows a great fit for the whole frequency range of interest with a normalized root mean square deviation of $99.49 \%$.

\section{Small Scale System and Model Verification}

A plug-in hybrid electric vehicle (PHEV) with a $50 \mathrm{~km}$ electric driving range is considered as reference system. The modeled vehicle should resemble a small passenger car as described in [9]. The used motor and vehicle parameter can be found in [9]. 9 battery packs are used, building up a total capacity of $10 \mathrm{kWh}$. Each battery pack consists of 150 cells, 10 in parallel and 15 in series. In this way a nominal battery pack voltage of about $50 \mathrm{~V}$ is achieved. Since the drive train of the vehicle operates in a wide range of frequency and torque, six characteristic operating points (OP), as can be seen in 
TABLE I: Cell parameters

\begin{tabular}{|c|c|c|c|c|c|c|c|c|}
\hline Measurement: & $\mathrm{R} 0[\mathrm{~m} \Omega]$ & $\mathrm{R} 1[\mathrm{~m} \Omega]$ & $\mathrm{R} 2[\mathrm{~m} \Omega]$ & $\mathrm{R} 3[\mathrm{~m} \Omega]$ & $\mathrm{C} 1[\mathrm{~F}]$ & $\mathrm{C} 2[\mathrm{~F}]$ & $\mathrm{C} 3[\mathrm{~F}]$ & Fit $[\%]$ \\
\hline meas $3.3 \mathrm{~V} 100 \mathrm{~Hz} 49 \mathrm{~A} 3 \mathrm{p} 3 \mathrm{z}$ & 0.16 & 2.55 & 2.05 & 1.26 & 0.13 & 1.92 & 65.31 & 98.63 \\
\hline meas $3.3 \mathrm{~V} 10 \mathrm{~Hz} 49 \mathrm{~A} 3 \mathrm{p} 3 \mathrm{z}$ & 10.41 & 2.67 & 1.58 & 1.21 & 0.20 & 4.11 & 84.65 & 99.40 \\
\hline meas $3.23 \mathrm{~V} 10 \mathrm{~Hz} 28 \mathrm{~A} 3 \mathrm{p} 3 \mathrm{z}$ & 9.76 & 1.96 & 1.43 & 1.21 & 0.35 & 3.43 & 33.06 & 99.42 \\
\hline meas $3.23 \mathrm{~V} 1 \mathrm{~Hz} 28 \mathrm{~A} 3 \mathrm{p} 3 \mathrm{z}$ & 10.02 & 2.47 & 1.41 & 1.37 & 0.49 & 9.93 & 168.94 & 99.49 \\
\hline meas $3.23 \mathrm{~V} 1 \mathrm{~Hz} 28 \mathrm{~A} 2 \mathrm{p} 2 \mathrm{z}$ & 11.07 & 2.60 & 1.45 & - & 1.98 & 110.98 & - & 99.23 \\
\hline meas $3.23 \mathrm{~V} 1 \mathrm{~Hz} 28 \mathrm{~A} 1 \mathrm{p} 1 \mathrm{z}$ & 13.04 & 1.90 & - & - & 41.61 & - & - & 97.92 \\
\hline meas $3.23 \mathrm{~V} 1 \mathrm{~Hz} 28 \mathrm{~A}$ Resistive & 14.61 & - & - & - & - & - & - & 93.99 \\
\hline
\end{tabular}
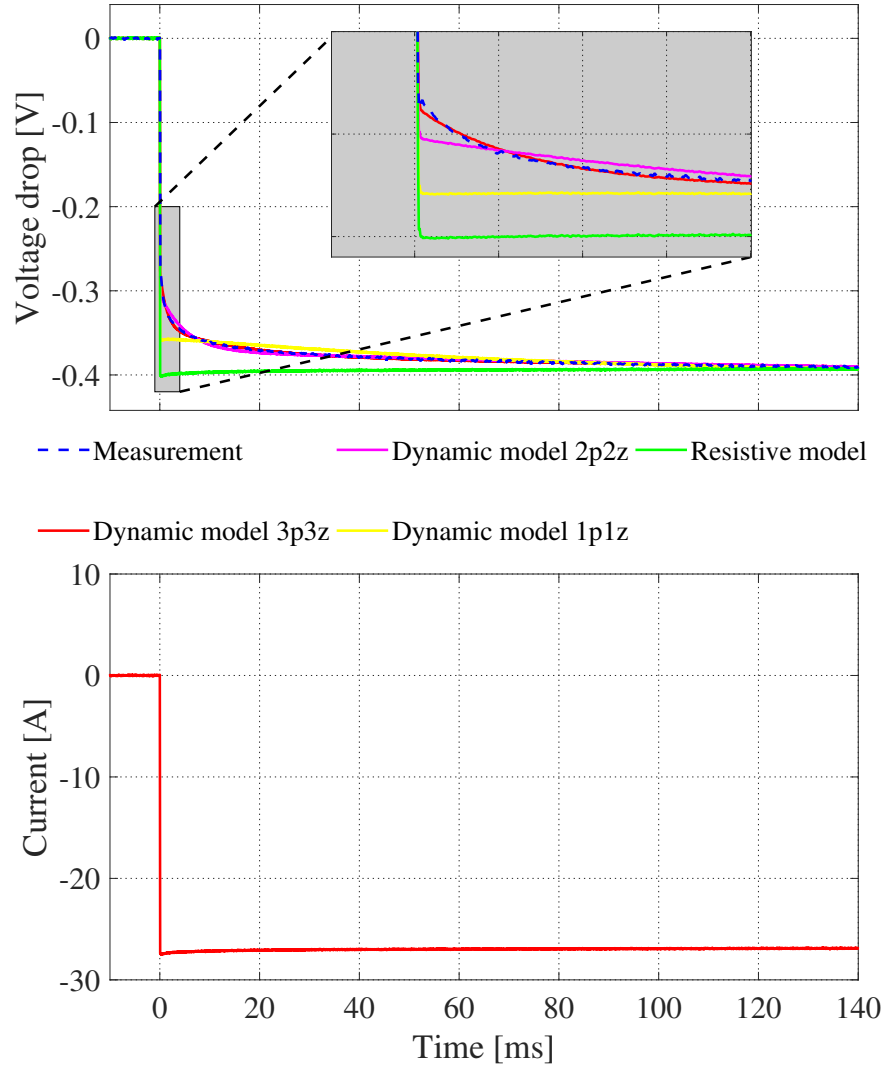

Fig. 5: Operating point at $1 \mathrm{~Hz}, 28 \mathrm{~A}(12.2 \mathrm{C})$ and $3.23 \mathrm{~V}$

TABLE II, are chosen to assess the behavior of the battery models [9]. To verify the dynamic behavior of the battery

TABLE II: Analyzed operating points for the vehicle in [9]

\begin{tabular}{cccrrr}
\hline OP & \multicolumn{1}{c}{ Speed } & T & $I_{\text {RMS }}$ & $V_{\text {phase }}$ & $\varphi$ \\
\hline 1 & 1000 RPM & $30 \mathrm{Nm}$ & $78 \mathrm{~A}$ & $17 \mathrm{~V}$ & $25 \mathrm{deg}$ \\
2 & $1000 \mathrm{RPM}$ & $60 \mathrm{Nm}$ & $137 \mathrm{~A}$ & $22 \mathrm{~V}$ & $36 \mathrm{deg}$ \\
3 & $1000 \mathrm{RPM}$ & $90 \mathrm{Nm}$ & $185 \mathrm{~A}$ & $28 \mathrm{~V}$ & $42 \mathrm{deg}$ \\
4 & $5000 \mathrm{RPM}$ & $30 \mathrm{Nm}$ & $78 \mathrm{~A}$ & $77 \mathrm{~V}$ & $27 \mathrm{deg}$ \\
5 & $5000 \mathrm{RPM}$ & $60 \mathrm{Nm}$ & $137 \mathrm{~A}$ & $103 \mathrm{~V}$ & $40 \mathrm{deg}$ \\
6 & $10000 \mathrm{RPM}$ & $30 \mathrm{Nm}$ & $101 \mathrm{~A}$ & $106 \mathrm{~V}$ & $1 \mathrm{deg}$ \\
\hline
\end{tabular}

models, using the characteristic operating points, a small scale drive system was used. The chosen small scale battery packs
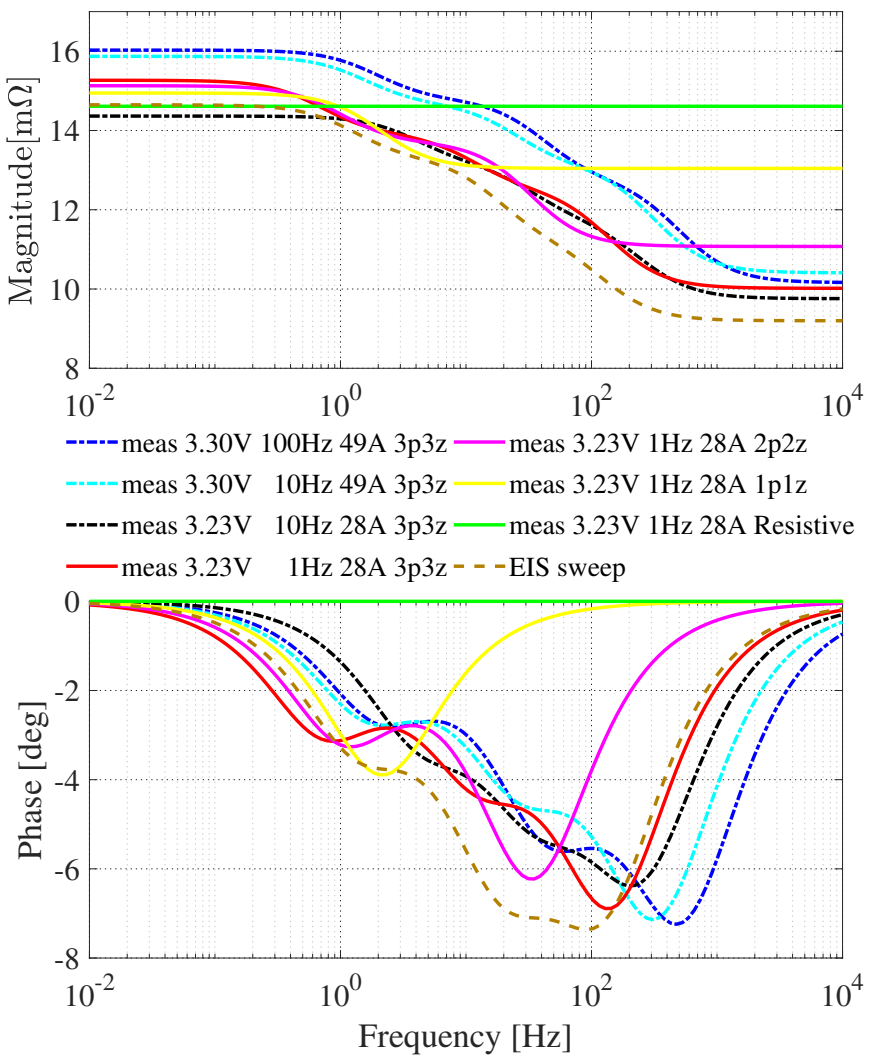

Fig. 6: Bode plot of the extracted battery impedances.

consist of 4 in series connected battery cells, which gives a nominal voltage of $13.2 \mathrm{~V}$ and a total capacity of $270 \mathrm{Wh}$. This results in a voltage ratio of the large and small scale system as

$$
\frac{V_{\text {LargeScale }}}{V_{\text {SmallScale }}}=\frac{N_{\text {ser,Large }}}{N_{\text {ser,Small }}}=\frac{50.0 \mathrm{~V}}{13.2 \mathrm{~V}} \approx 3.8
$$

and a current ratio according to the capacity as

$$
\frac{C_{\text {LargeScale }}}{C_{\text {SmallScale }}}=\frac{10 \mathrm{kWh}}{0.27 \mathrm{kWh}}=\frac{I_{\text {LargeScale }} V_{\text {LargeScale }}}{I_{\text {SmallScale }} V_{\text {SmallScale }}}
$$

which results in

$$
\frac{I_{\text {LargeScale }}}{I_{\text {SmallScale }}} \approx 9.7
$$

To get the same operating points for the small scale system, the operating points in TABLE II are down-scaled according 
to (13) and (15) and are shown in Table III. In this way, each single cell is stressed with the same current as in the example hybrid vehicle. The built small scale setup can be seen in

TABLE III: Analyzed operating points for the lab setup

\begin{tabular}{rrcrrr}
\hline OP & \multicolumn{1}{c}{ Speed } & T & $I_{\text {RMS }}$ & $V_{\text {phase }_{\text {RMS }}}$ & $\varphi$ \\
\hline 1 & 1000 RPM & $30 \mathrm{Nm}$ & $8 \mathrm{~A}$ & $4 \mathrm{~V}$ & $25 \mathrm{deg}$ \\
2 & $1000 \mathrm{RPM}$ & $60 \mathrm{Nm}$ & $14 \mathrm{~A}$ & $6 \mathrm{~V}$ & $36 \mathrm{deg}$ \\
3 & $1000 \mathrm{RPM}$ & $90 \mathrm{Nm}$ & $19 \mathrm{~A}$ & $7 \mathrm{~V}$ & $42 \mathrm{deg}$ \\
4 & $5000 \mathrm{RPM}$ & $30 \mathrm{Nm}$ & $8 \mathrm{~A}$ & $20 \mathrm{~V}$ & $27 \mathrm{deg}$ \\
5 & $5000 \mathrm{RPM}$ & $60 \mathrm{Nm}$ & $14 \mathrm{~A}$ & $27 \mathrm{~V}$ & $40 \mathrm{deg}$ \\
6 & $10000 \mathrm{RPM}$ & $30 \mathrm{Nm}$ & $10 \mathrm{~A}$ & $28 \mathrm{~V}$ & $1 \mathrm{deg}$ \\
\hline
\end{tabular}

Fig. 7. A small induction machine is driven by the MLI. The open circuit voltage $V_{\mathrm{OCV}}$ of the battery can be estimated using coulomb counting or using a more advanced estimator. The product of the measured battery voltage drop and the battery current yields the battery losses, so that the simulated and measured battery losses can easily be compared with each other. Fig. 8 shows the drawn battery current and the measured voltage drop waveform in comparison to the simulated voltage drop for operating point 5 . It can be seen that the $3 \mathrm{p} 3 \mathrm{z}$ dynamic model follows the measurement very well both for higher frequencies but also for the lower ones. The $2 \mathrm{p} 2 \mathrm{z}$ model agrees quite well with the measurement as well, and only overestimates the voltage drop with a few percents. The $1 \mathrm{p} 1 \mathrm{z}$ and the resistive model do however not agree well with the measurements and overestimate the voltage drop when a current is flowing in the cell (higher losses) and underestimate the voltage drop when no current is flowing through the cell (relaxation). As a total, the resistive model overestimates the losses except for when a pure DC-current is flowing in the cells. However, this never occurs in a multilevel inverter drive system. The EIS model underestimates the voltage drop and therefore the losses.

NP-connection Data aquasition \& control

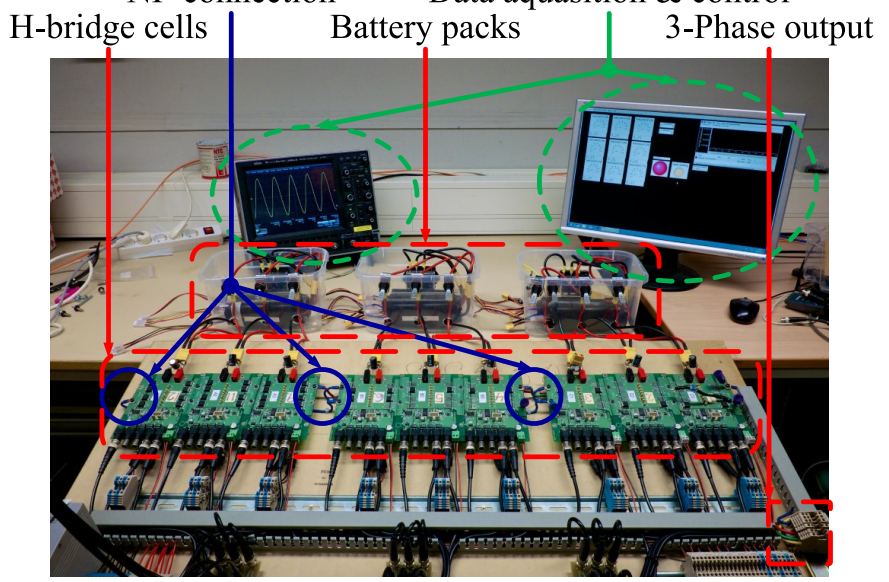

Fig. 7: Small scale CHB inverter setup.

The resulting losses are shown in Fig. 9 and the relative maximum voltage drop compared to the measurements can be seen in Table IV. It can be noted that the dynamic model and the measurements agree very well and that the
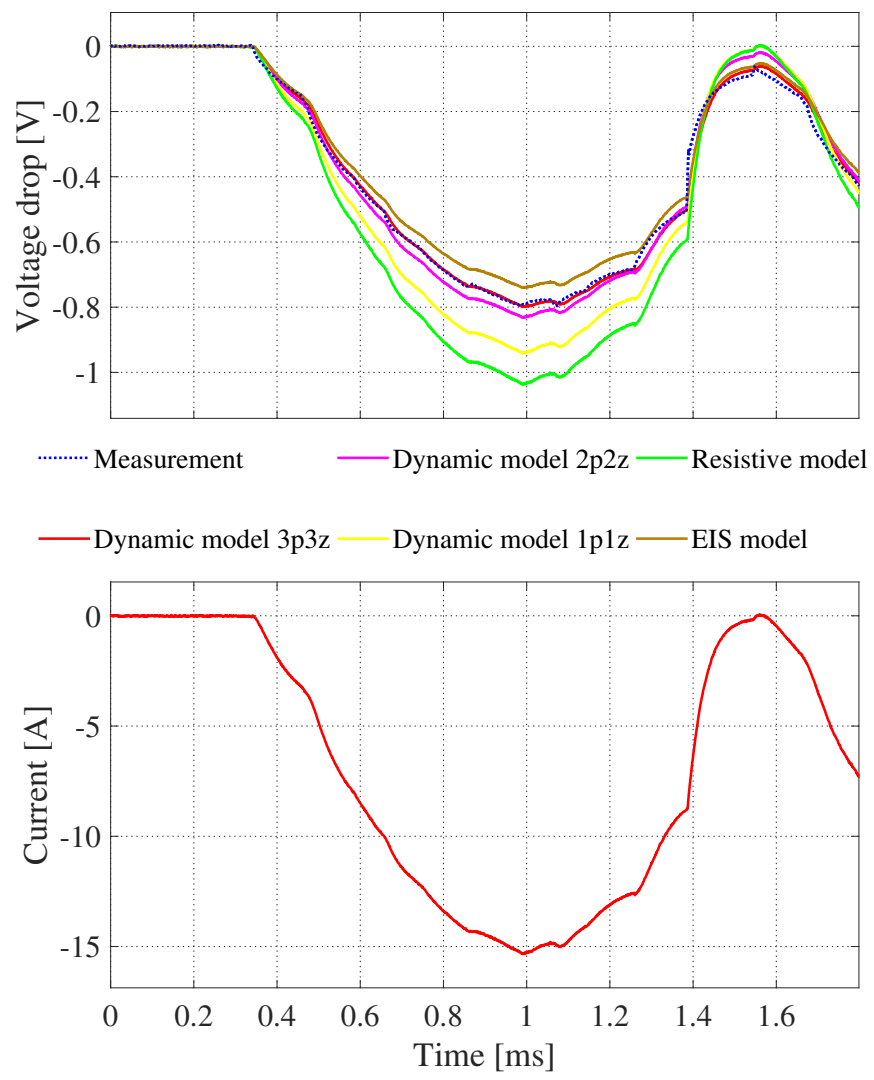

Fig. 8: Battery voltage drop and current for operating point 5.

resistive model always overestimates the losses and the EIS model underestimates the losses. It can also be noted that the resistive model shows a better agreement at lower frequencies (operating point 1) compared to higher frequencies (operating point 6).

TABLE IV: Maximum voltage drop for the six operating points relative to the measurement

\begin{tabular}{crrrrrr}
\hline Model & 1 & 2 & \multicolumn{1}{c}{3} & \multicolumn{1}{c}{4} & \multicolumn{1}{c}{5} & 6 \\
\hline Measurement & $100 \%$ & $100 \%$ & $100 \%$ & $100 \%$ & $100 \%$ & $100 \%$ \\
$3 \mathrm{p} 3 \mathrm{z}$ & $98 \%$ & $101 \%$ & $98 \%$ & $101 \%$ & $100 \%$ & $102 \%$ \\
$2 \mathrm{p} 2 \mathrm{z}$ & $98 \%$ & $101 \%$ & $101 \%$ & $105 \%$ & $104 \%$ & $108 \%$ \\
$1 \mathrm{p} 1 \mathrm{z}$ & $107 \%$ & $111 \%$ & $112 \%$ & $119 \%$ & $118 \%$ & $123 \%$ \\
Resistive & $118 \%$ & $122 \%$ & $124 \%$ & $131 \%$ & $130 \%$ & $136 \%$ \\
EIS & $91 \%$ & $94 \%$ & $91 \%$ & $94 \%$ & $93 \%$ & $95 \%$ \\
\hline
\end{tabular}

\section{Drive Cycle Evaluation}

Simulations are used to assess the behavior of the battery models for different driving cycles. The compact reference car and the electric motor described in [9] are used to calculate the drive cycle operating points for the inverter. Four typical driving cycles were chosen to cover the characteristic vehicle loads for city driving (FTP75), highway driving (HWFET), aggressive driving (HWFET) and test procedure driving (NEDC). The resulting total battery losses can be seen in Fig. 10. It can be noted that a similar relation between the models is shown 


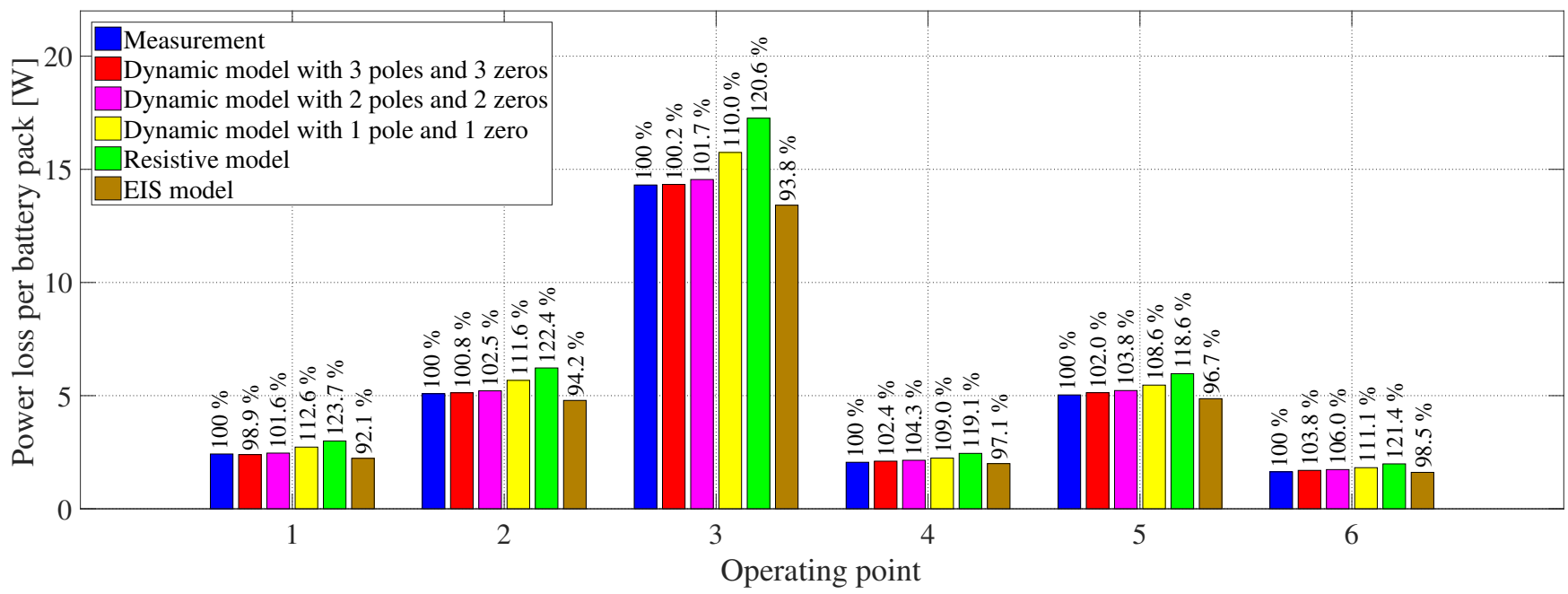

Fig. 9: Loss comparison between measurements, different dynamic models and a pure resistive model for the six characteristic operating points.

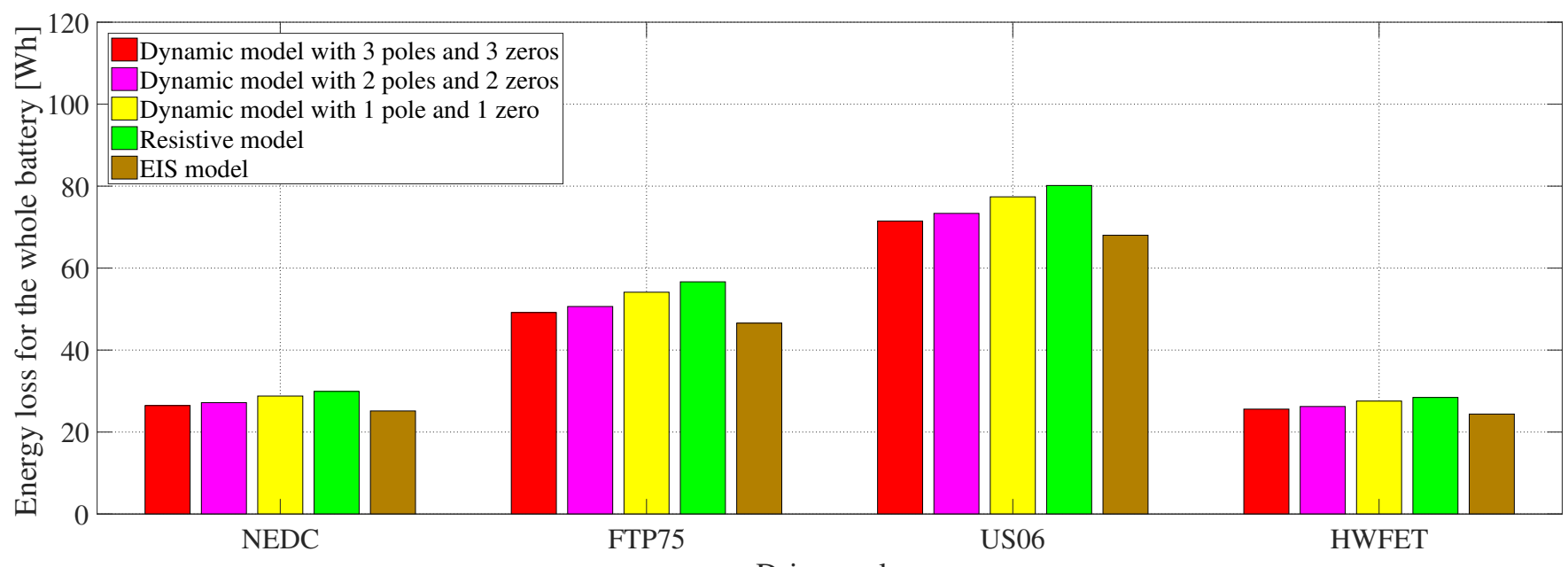

Drive cycle

Fig. 10: Comparison between the simulated battery losses for different drive cycles.

for all the driving cycles, even though the vehicle operates at different speeds and accelerations in the four driving cycles. In the same way as for the single operating point verification, the resistive model shows higher losses compared to the $3 \mathrm{p} 3 \mathrm{z}$ dynamic model and the EIS model provides a lower loss prediction.

\section{CONCLUSION}

In comparison to a two-level inverter, the battery packs in a cascaded H-bridge multilevel inverter are stressed with a substantial amount of low order current harmonics. Therefore, this paper dealt with the modeling and drive cycle loss evaluation of the battery packs used in a seven level CHB inverter. A down-scaled drive system was used to verify and to compare theory and simulation results. It has been shown that a simple measurement of a pulsed current can be used to determine the parameters of the Randles model, using up to three time constants. When evaluated at the chosen six drive train operating points, the accuracy of a two or three time constant system is very good in comparison to the measurements. It has been shown that a pure resistive battery model overestimates the battery losses to a great extent by about $20 \%$, whereas a single time constant system overestimates the losses by about $10 \%$. Furthermore, it has been seen that the battery parameters extracted from the electric impedance spectroscopy underestimate the battery losses by about $1.5 \%$ to $8 \%$. The simulation results from the drive cycle analysis have shown the same characteristics as the six operating points.

\section{REFERENCES}

[1] A. Bubert, K. Oberdieck, H. Xu, and R. W. De Doncker, "Experimental validation of design concepts for future ev-traction inverters," in 2018 IEEE Transportation Electrification Conference and Expo (ITEC), June 2018, pp. 795-802.

[2] E. A. Grunditz and T. Thiringer, "Performance analysis of current bevs based on a comprehensive review of specifications," IEEE Transactions on Transportation Electrification, vol. 2, no. 3, pp. 270-289, Sep. 2016. 
[3] E. Arfa Grunditz and T. Thiringer, "Characterizing bev powertrain energy consumption, efficiency, and range during official and drive cycles from gothenburg, sweden," IEEE Transactions on Vehicular Technology, vol. 65, no. 6, pp. 3964-3980, June 2016.

[4] L. M. Tolbert, F. Z. Peng, and T. G. Habetler, "Multilevel inverters for electric vehicle applications," in Power Electronics in Transportation (Cat. No.98TH8349), Oct 1998, pp. 79-84.

[5] A. Kersten, K. Oberdieck, A. Bubert, M. Neubert, E. Grunditz, T. Thiringer, and R. W. De Doncker, "Fault detection and localization for limp home functionality of three-level npc inverters with connected neutral point for electric vehicles," IEEE Transactions on Transportation Electrification, pp. 1-1, 2019.

[6] A. Kersten, E. Grunditz, and T. Thiringer, "Efficiency of active threelevel and five-level npc inverters compared to a two-level inverter in a vehicle," in 2018 20th European Conference on Power Electronics and Applications (EPE'18 ECCE Europe), Sep. 2018, pp. P.1-P.9.

[7] H. Xu, A. Bubert, M. Laumen, and R. W. De Doncker, "Active neutralpoint balancing of three-level neutral-point-clamped traction inverters," in 2018 21st International Conference on Electrical Machines and Systems (ICEMS), Oct 2018, pp. 2256-2261.

[8] O. Josefsson, A. Lindskog, S. Lundmark, and T. Thiringer, "Assessment of a multilevel converter for a phev charge and traction application," in The XIX International Conference on Electrical Machines-ICEM 2010. IEEE, 2010, pp. 1-6.

[9] O. Josefsson, Investigation of a Multilevel Inverter for Electric Vehicle Applications, ser. Doctoral Thesis at Chalmers University of Technology. Institute of Energy and Environment, Chalmers University of Technology, 2015, 146.

[10] F. Helling, M. Kuder, A. Singer, S. Schmid, and T. Weyh, "Low voltage power supply in modular multilevel converter based split battery systems for electrical vehicles," in 2018 20th European Conference on Power Electronics and Applications (EPE'18 ECCE Europe), Sep. 2018, pp. P.1-P.10.

[11] Z. Zheng, K. Wang, L. Xu, and Y. Li, "A hybrid cascaded multilevel converter for battery energy management applied in electric vehicles," IEEE Transactions on power electronics, vol. 29, no. 7, pp. 3537-3546, 2014.

[12] M. R. Jongerden and B. R. Haverkort, "Which battery model to use?" IET software, vol. 3, no. 6, pp. 445-457, 2009.

[13] M. Einhorn, F. V. Conte, C. Kral, and J. Fleig, "Comparison, selection, and parameterization of electrical battery models for automotive applications," IEEE Transactions on Power Electronics, vol. 28, no. 3, pp. 1429-1437, 2013.

[14] G. L. Plett, "High-performance battery-pack power estimation using a dynamic cell model," IEEE Transactions on vehicular technology, vol. 53, no. 5, pp. 1586-1593, 2004.

[15] B. Enache, E. Lefter, and C. Stoica, "Comparative study for generic battery models used for electric vehicles," in 2013 8TH INTERNATIONAL SYMPOSIUM ON ADVANCED TOPICS IN ELECTRICAL ENGINEERING (ATEE). IEEE, 2013, pp. 1-6.

[16] S. Skoog and S. David, "Parameterization of linear equivalent circuit models over wide temperature and soc spans for automotive lithium-ion cells using electrochemical impedance spectroscopy," Journal of Energy Storage, vol. 14, pp. 39-48, 2017.

[17] R. C. Kroeze and P. T. Krein, "Electrical battery model for use in dynamic electric vehicle simulations," in 2008 IEEE Power Electronics Specialists Conference. IEEE, 2008, pp. 1336-1342.
[18] X. Hu, S. J. Moura, N. Murgovski, B. Egardt, and D. Cao, "Integrated optimization of battery sizing, charging, and power management in plug-in hybrid electric vehicles," IEEE Transactions on Control Systems Technology, vol. 24, no. 3, pp. 1036-1043, 2016.

[19] A. Hentunen, T. Lehmuspelto, and J. Suomela, "Electrical battery model for dynamic simulations of hybrid electric vehicles," in 2011 IEEE Vehicle Power and Propulsion Conference. IEEE, 2011, pp. 1-6.

[20] L. Y. Wang, M. P. Polis, G. G. Yin, W. Chen, Y. Fu, and C. C. Mi, "Battery cell identification and soc estimation using string terminal voltage measurements," IEEE transactions on vehicular technology, vol. 61, no. 7, pp. 2925-2935, 2012.

[21] A. Hentunen, T. Lehmuspelto, and J. Suomela, "Time-domain parameter extraction method for thévenin-equivalent circuit battery models," ieee transactions on energy conversion, vol. 29, no. 3, pp. 558-566, 2014.

[22] S. Skoog, "Parameterization of equivalent circuit models for high power lithium-ion batteries in hev applications," in 2016 18th European Conference on Power Electronics and Applications (EPE'16 ECCE Europe), Sep. 2016, pp. 1-10.

[23] K. Sharifabadi, L. Harnefors, H.-P. Nee, S. Norrga, and R. Teodorescu, Design, control, and application of modular multilevel converters for HVDC transmission systems. John Wiley \& Sons, 2016.

[24] M. S. A. Dahidah and V. G. Agelidis, "Selective harmonic elimination multilevel converter control with variant dc sources," in 2009 4th IEEE Conference on Industrial Electronics and Applications, May 2009, pp. 3351-3356.

[25] P. Cortes, A. Wilson, S. Kouro, J. Rodriguez, and H. Abu-Rub, "Model predictive control of multilevel cascaded h-bridge inverters," IEEE Transactions on Industrial Electronics, vol. 57, no. 8, pp. 2691-2699, Aug 2010.

[26] and F. Z. Peng, "Harmonics optimization of the voltage balancing control for multilevel converter/inverter systems," IEEE Transactions on Power Electronics, vol. 21, no. 1, pp. 211-218, Jan 2006.

[27] H. Lou, C. Mao, D. Wang, J. Lu, and L. Wang, "Fundamental modulation strategy with selective harmonic elimination for multilevel inverters," IET Power Electronics, vol. 7, no. 8, pp. 2173-2181, August 2014.

[28] E. Guan, P. Song, M. Ye, and B. Wu, "Selective harmonic elimination techniques for multilevel cascaded h-bridge inverters," in 2005 International Conference on Power Electronics and Drives Systems, vol. 2, Nov 2005, pp. 1441-1446.

[29] S. Haghbin and T. Thiringer, "Dc bus current harmonics of a threephase pwm inverter with the zero sequence injection," in 2014 IEEE Transportation Electrification Conference and Expo (ITEC), June 2014, pp. 1-6.

[30] A. Karvonen and T. Thiringer, "Parameter analysis of current and voltage ripple in a hybrid vehicle traction system," in 2015 IEEE International Electric Machines \& Drives Conference (IEMDC). IEEE, 2015, pp. 1838-1845.

[31] S. Haghbin, A. Rabiei, and T. Thiringer, "High-frequency modelling of a three-phase pulse width modulation inverter towards the dc bus considering line and controller harmonics," The Journal of Engineering, vol. 2014, no. 10, pp. 581-589, 2014.

[32] A123 Systems, High Power Lithium Ion ANR26650M1A, mD100001-02 datasheet, 2009-2010.

[33] "Gamry reference 3000 potentiostat/galvanostat/zra," https://www. gamry.com/potentiostats/reference-3000/, (Accessed on 04/19/2019). 